
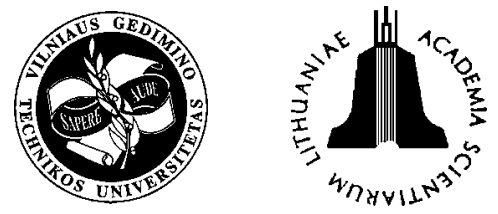

JOURNAL OF CIVIL ENGINEERING AND MANAGEMENT

http:/www.vtu.lt/english/editions

2004, Vol X, No 3, 209-215

\title{
FLEXURAL CAPACITY OF CONCRETE BEAMS REINFORCED WITH STEEL AND FIBRE-REINFORCED POLYMER (FRP) BARS
}

\author{
Hau Yan Leung \\ Dept of Civil Engineering, Chu Hai College, Yi Lok Street, Riviera Gardens, Tsuen Wan, N.T., Hong Kong. \\ E-mail: brianleung@chuhai.edu.hk
}

Received 4 March 2004; accepted 21 Apr 2004

\begin{abstract}
Although much research on concrete beams reinforced with fibre-reinforced polymer (FRP) rods has been conducted in recent years, their use still does not receive the attention it deserves from practicising engineers. This is attributed to the fact that FRP is brittle in nature and the collapse of FRP-reinforced concrete member may be catastrophic. A rational beam design can incorporate a hybrid use of FRP rods and steel rods. Current design codes only deal with steel-reinforced or FRP-reinforced concrete members. Therefore in this study some design charts and equations for concrete beam sections reinforced with FRP rods and steel rebars were generated. Results from the theoretical derivations agreed well with experimental data.
\end{abstract}

Keywords: concrete, beam, flexural capacity, FRP, steel.

\section{Introduction}

The ultimate capacity of the concrete beam has been adopted as one of the design criteria in some design codes [1-3] for many years. These codes provide design equations and charts for steel reinforced concrete members only. Today, a novel material known as fibre-reinforced polymer (FRP) composite has been developed. FRP is manufactured through a pultrusion process and it usually contains a bundle of artificial fibres embedded in a resin matrix. Three common kinds of fibres are carbon, glass and aramid. Being used together with different resins, such as epoxy and vinyl ester, and different surface profiles, such as sand-coated and fibre wrapping, a variety of FRP products is thus commercially available. The excellent properties of FRP include high strength-toweight ratio, good fatigue resistance, non-corrosive, nonelectromagnetic and high resistance to chemical attack and due to these superiorities over a conventional steel, FRP has been widely suggested by researchers to be incorporated in concrete design. A lot of research results pertaining to the investigation of concrete beams reinforced with FRP rods has emerged recently [4-11].

Nonetheless, it has been reckoned that the brittleness of FRP hinders further developments in concrete structures. A more rational use of FRP in concrete beams is to adopt a mix of FRP rods and steel rebars, so that the beam ductility at its ultimate can be provided by the steel rebars. Since the characteristics of FRP are different from those of steel, it can be conceived that current design formulas for reinforced concrete (RC) with steel bars may not be applicable to RC with FRP bars. In order to work out the flexural strength of concrete beams reinforced with FRP rods and steel rebars, some design charts or equations are necessary. The present work describes a prediction model of the flexural strength of concrete beams embedded with FRP rods and steel rebars and the results from the prediction model agreed with the experimental data with reasonable accuracy.

\section{Theoretical derivations}

Four major assumptions in the ensuing derivations are:

- Linear strain variation across the section;

- Tension concrete ignored;

- The non-linear stress profile of concrete is modelled by an equivalent rectangular stress block;

The stresses of steel rebars and FRP rods can be derived from their corresponding stress-strain curves.

By adopting two kinds of reinforcement inside a beam section, it is more appropriate to place the FRP rods closer to the bottom of the section. It is because FRP has a higher resistance to external attack, such as corrosion and chemical reaction; and more importantly, a higher degree of protection to steel can be achieved when the steel rebars are located further from the concrete surfaces. With this rationale in mind, the steel rebar layer is likely to be at a smaller lever arm than that of FRP rods. 


\subsection{Balanced section}

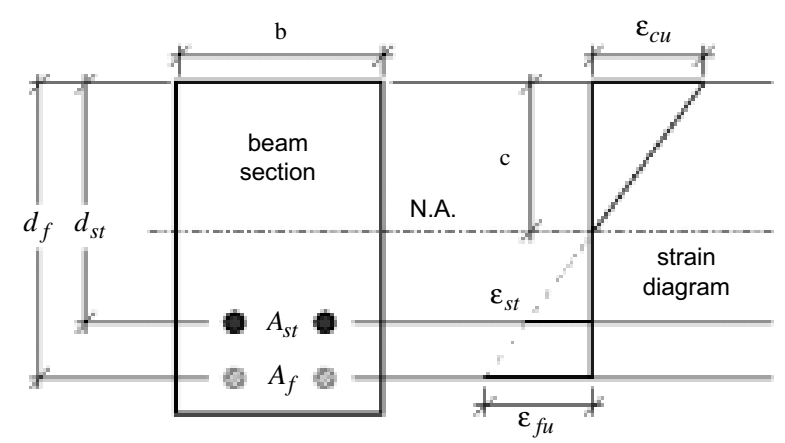

Fig 1. Balanced ultimate condition

Fig 1 illustrates a concrete beam section internally reinforced with steel rebars and FRP rods and their crosssectional areas are $A_{s t}$ and $A_{f}$ respectively. Since the FRP rods are used as the primary reinforcement and steel as secondary, the depth of the steel rebars $\left(d_{s t}\right)$ is thus proposed to be less than that of FRP rods $\left(d_{f}\right)$, ie FRP rods are placed closer to the bottom of the beam. When the beam section in flexure reaches a balanced ultimate condition, crushing of compression concrete and rupture of FRP rods occur simultaneously (Fig 1). If a linear strain distribution across the section is assumed, the neutral axis position $(c)$ at balanced ultimate condition can be easily determined by (1).

$$
\frac{c}{d_{f}}=\frac{\varepsilon_{c u}}{\varepsilon_{c u}+\varepsilon_{f u}},
$$

where $\varepsilon_{c u}$ - ultimate strain of compression concrete and $\varepsilon_{f u}-$ ultimate strain of FRP rods. The linear strain profile also leads to (2).

$$
\frac{d_{s t}}{c}=\frac{\varepsilon_{c u}+\varepsilon_{s t}}{\varepsilon_{c u}},
$$

where $\varepsilon_{s t}$ is the strain of steel rebars. By combining (1) and (2), it gives

$$
\frac{d_{s t}}{d_{f}}=\frac{\varepsilon_{c u}+\varepsilon_{s t}}{\varepsilon_{c u}+\varepsilon_{f u}} .
$$

Equation (3) indicates that the depth of steel rebars is governed by the strain values of concrete, FRP rods and steel rebars. It is apparent that when $d_{s t}$ is smaller than $c$, the steel rebars will be subject to compression. Therefore in order to avoid compressive steel rebars, $d_{s t} \geq c$ must be satisfied and the limiting value of $d_{s t}$ is $c$. If the limiting case is considered, the steel rebars are in fact located at the neutral axis and $\varepsilon_{s t}=0$ results. Equation (3) then reduces to (1). On the other hand, when $d_{s t}$ is increased, $\varepsilon_{s t}$ increases as well. At the onset of steel yielding, $\varepsilon_{s t}$ reaches the yield strain of steel $\left(\varepsilon_{y}\right)$ and the value of $d_{s t}$ to cause steel yielding can be obtained by (4)

$$
\frac{d_{s t}}{d_{f}}=\frac{\varepsilon_{c u}+\varepsilon_{y}}{\varepsilon_{c u}+\varepsilon_{f u}} .
$$

By changing the value of $\varepsilon_{f u}$, the limiting ratios of $d_{s t}$ and $d_{f}$ for both zero steel strain and onset of steel yielding can be easily calculated by (1) and (4). In the ensuing derivations, $\varepsilon_{c u}=0,0035$ is assumed.

As shown in Fig 2, (1) and (4) divide the $d_{s t} / d_{f}-$ $\varepsilon_{f u}$ space into three different regions. In region 1 , the ratio of $d_{s t} / d_{f}$ is larger than its value at the onset of steel yielding for a particular value of $\varepsilon_{f u}$, the steel rebars thus yield at the balanced ultimate condition of the beam section. However, in region 2 , the $d_{s t} / d_{f}$ ratio is less than the yielding value of $d_{s t} d_{f}$, the steel rebars remain elastic at ultimate. In region $3, d_{s t}<c$ and compression steel rebars are obtained. In the present study, the beam section in the first two regions will be examined.

\subsection{Classification of section}

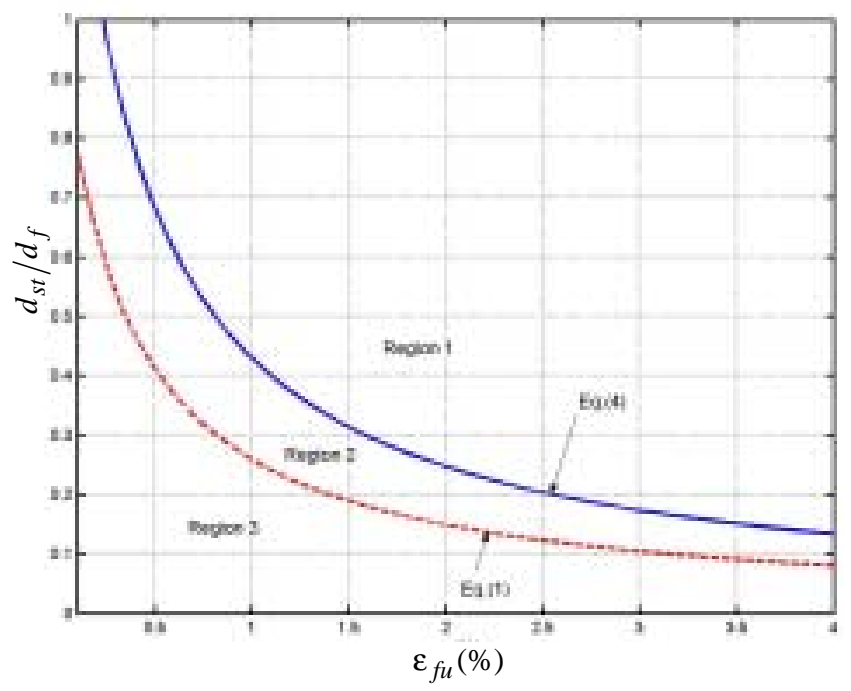

Fig 2. $\frac{d_{s t}}{d_{f}}$ against $\varepsilon_{f u}$ at balanced ultimate condition

Having established the value of $\varepsilon_{f u}$, the value of $d_{s t} / d_{f}$ ratio in the region 1 can then be easily chosen from Fig 2. It should be noted that $\varepsilon_{s t}>\varepsilon_{y}$ and the steel stress $\left(f_{s t}\right)$ equals its yield stress $\left(f_{y}\right)$ at the ultimate stage of the balanced beam section (Fig 3). Internal force equilibrium of the section leads to

$$
\left(0,85 f_{c}^{\prime}\right) \times\left(\beta_{1} c\right) \times b=A_{s t} f_{y}+A_{f} f_{f u},
$$

where $f_{c}^{\prime}$ - concrete cylinder compressive strength (in $\mathrm{MPa}), \beta_{1}$ - ratio of the equivalent rectangular stress block depth to the neutral axis depth, $b$ - beam breadth and $f_{f u}-$ ultimate tensile strength of FRP rods.

Rearrangement of (5) gives

$$
0,85 f_{c}^{\prime} \beta_{1}\left(\frac{c}{d_{f}}\right)=\left(\frac{A_{f}}{b d_{f}}\right) f_{f u}+\left(\frac{A_{s t}}{b d_{s t}}\right)\left(\frac{d_{s t}}{d_{f}}\right) f_{y} .
$$




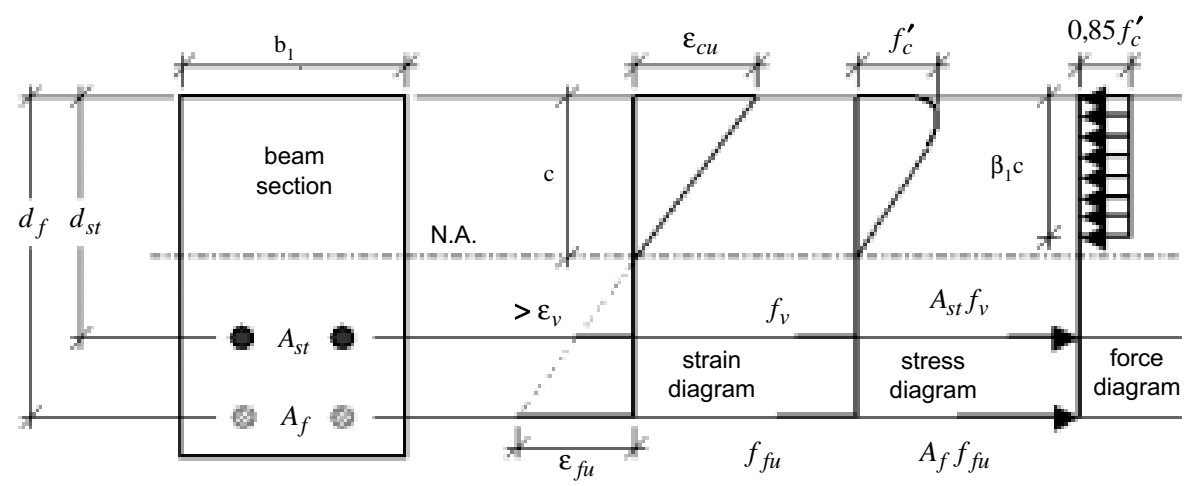

Fig 3. Balanced beam section design (region 1)

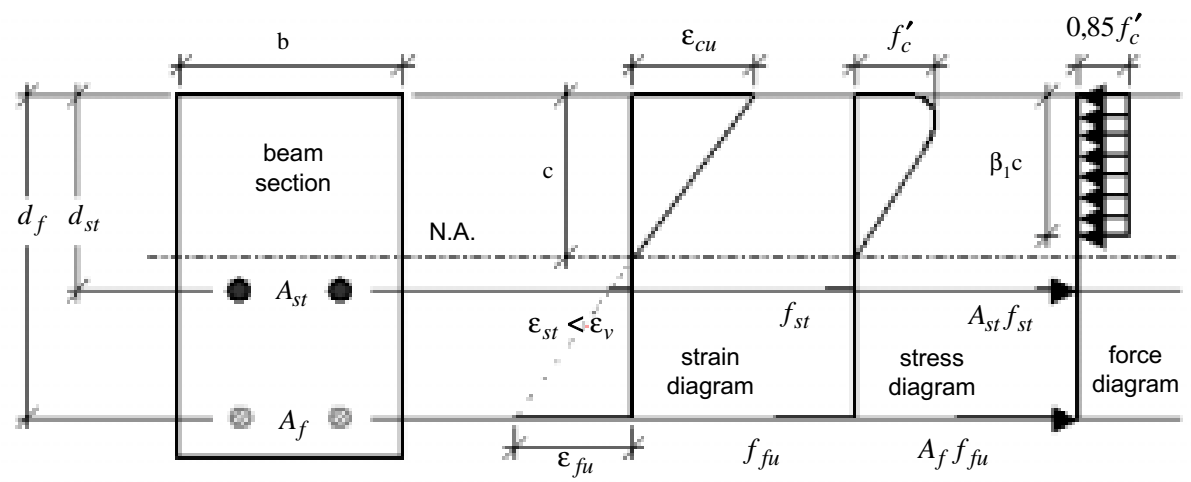

Fig 4. Balanced beam section design (region 2)

It should be noted that (6) describes the relationship between $\left(A_{f} / b d_{f}\right)$ and $\left(A_{s t} / b d_{s t}\right)$ for a balanced beam section in region 1 .

In contrast, the steel rebars inside the beam section in region 2 of Fig 2 remain in its elastic range and steel yielding does not occur. By considering the internal force equilibrium again (Fig 4), it gives

$$
\left(0,85 f_{c}^{\prime}\right) \times\left(\beta_{1} c\right) \times b=A_{s t} f_{s t}+A_{f} f_{f u} .
$$

It is noteworthy that $f_{s t}$ in (7) is smaller than $f_{y}$. Rearrangement of (7) gives rise to

$$
0,85 f_{c}^{\prime} \beta_{1}\left(\frac{c}{d_{f}}\right)=\left(\frac{A_{f}}{b d_{f}}\right) f_{f u}+\left(\frac{A_{s t}}{b d_{s t}}\right)\left(\frac{d_{s t}}{d_{f}}\right) f_{s t} .
$$

The elastic behaviour of steel rebars can be described by

$$
f_{s t}=E_{s t} \times \varepsilon_{s t},
$$

where $E_{s t}$ denotes the elastic modulus of steel rebars. From the strain diagram in Fig 4, the steel strain can be calculated by

$$
\varepsilon_{s t}=\left(\frac{d_{s t}-c}{c}\right) \varepsilon_{c u} .
$$

Substitute (10) into (9), it gives

$$
f_{s t}=E_{s t} \times\left[\frac{\left(d_{s t} / d_{f}\right)}{\left(c / d_{f}\right)}-1\right] \times \varepsilon_{c u} .
$$

Then, by putting (11) into (8), the variation of $\left(A_{f} / b d_{f}\right)$ against $\left(A_{s t} / b d_{s t}\right)$ for a balanced beam section in region 2 is obtained:

$$
\begin{aligned}
& 0,85 f_{c}^{\prime} \beta_{1}\left(\frac{c}{d_{f}}\right)=\left(\frac{A_{f}}{b d_{f}}\right) f_{f u}+ \\
& \left(\frac{A_{s t}}{b d_{s t}}\right)\left(\frac{d_{s t}}{d_{f}}\right)\left(E_{s t} \varepsilon_{c u}\right) \times\left[\frac{\left(d_{s t} / d_{f}\right)}{\left(c / d_{f}\right)}-1\right] .
\end{aligned}
$$

By using (7) and (12), the variation of $\left(A_{f} b d_{f}\right)$ against $\left(A_{s t} b d_{s t}\right)$ for any balanced beam sections in regions 1 and 2 of Fig 2 can be calculated. To initiate the generation of such a plot, $\varepsilon_{f u}=1,5 \%$ is selected. From Fig 2, the limiting value for compression steel, $c / d_{f}=0,19$ and the value for steel yielding, $d_{s t} d_{f}=0,31$ are obtained. Generation of the $\left(A_{f} b d_{f}\right)-\left(A_{s t} b d_{s t}\right)$ plot requires other input parameters and they include $f_{c}=40 \mathrm{MPa}$, $\beta_{1}=0,85-0,05 \times\left(f_{c u}-27,6\right) / 6,7, \quad f_{f u}=600 \mathrm{MPa}$, $f_{y}=460 \mathrm{MPa}$ and $E_{s t}=200 \mathrm{GPa}$. Using this data, a typical $\left(A_{f} / b d_{f}\right)_{-}\left(A_{s t} / b d_{s t}\right)$ plot can then be devel- 


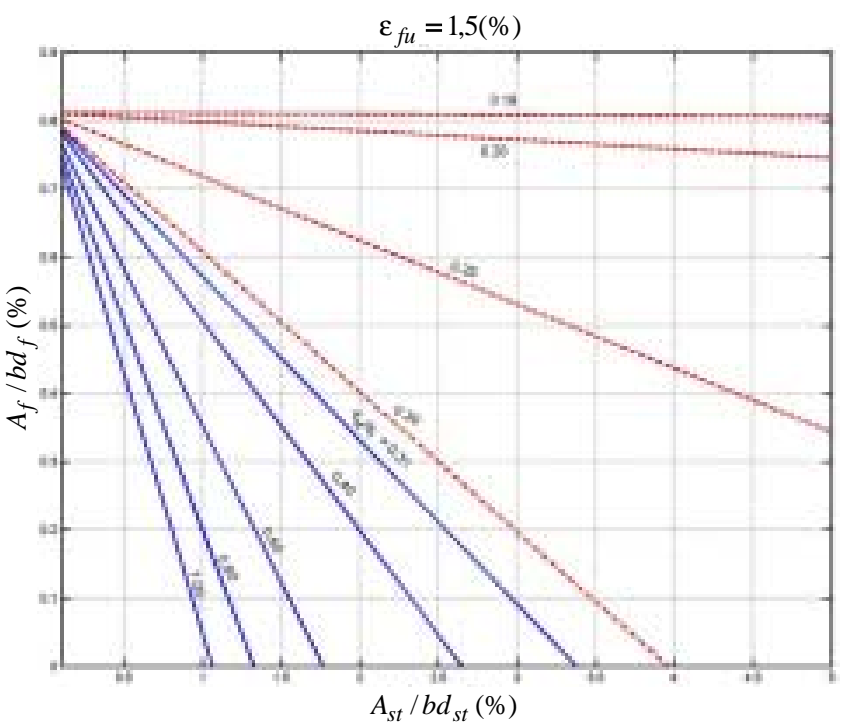

Fig 5. $\frac{A_{f}}{b d_{f}}$ against $\frac{A_{s t}}{b d_{s t}}$

oped and it is given in Fig 5. In Fig 5, the values of $\left(A_{f} / b d_{f}\right)$ and $\left(A_{s t} / b d_{s t}\right)$ for different ratios of $d_{s t} / d_{f}$ are shown. The solid lines $\left(d_{s t} / d_{f}>0,31\right)$ indicate that the steel rebars yield at the ultimate state of the balanced beam section whereas the dotted lines $\left(d_{s t} / d_{f}<0,31\right)$ show that the steel rebars are in its elastic range. It is clear from Fig 5 that there is an inverse relationship between $\left(A_{f} b d_{f}\right)$ and $\left(A_{s t} b d_{s t}\right)$ for every value of $d_{s t} d_{f}$. To maintain a balanced beam section, an increase in $\left(A_{s t} / b d_{s t}\right)$ always leads to a reduction in $\left(A_{f} b d_{f}\right)$ and vice versa. By using this plot, one may manipulate the combinations of $\left(A_{f} / b d_{f}\right)$ and $\left(A_{s t} b d_{s t}\right)$ so as to achieve a balanced section in region 1 or region 2 .

In Fig 5, each line represents a balanced beam section in which the steel yields or does not yield at the ultimate state. For example, when the solid line for $d_{s t} / d_{f}=0,4$ is considered, this line gives the balanced ratio of $\left(A_{f} b d_{f}\right)$ once $\left(A_{s t} / b d_{s t}\right)$ has been determined. When a higher ratio of $\left(A_{f} b d_{f}\right)$ is used, the section becomes over-reinforced whereas an under-reinforced section will be obtained when a reduced value of $\left(A_{f} b d_{f}\right)$ is adopted. It is interesting to observe that when $A_{s t} / b d_{s t}>2,6 \%$, the section will become overreinforced irrespective of the $\left(A_{f} / b d_{f}\right)$ ratio. When $d_{s t} / d_{f}=0,3$ is chosen, the limiting value of $A_{s t} / b d_{s t}$ becomes 4,0\% approximately. One may therefore conclude that the $\left(A_{f} b d_{f}\right)_{-}\left(A_{s t} / b d_{s t}\right)$ plot is useful in that the classification of designed beam sections can be readily obtained.

\subsection{Flexural Capacity}

To determine the nominal flexural capacity of the beam section at ultimate state, one may need to consider over-reinforced and under-reinforced sections in regions 1 and 2 separately.

In region 1, when an over-reinforced beam section is adopted, ie concrete crushes and steel yields at ultimate. Internal force equilibrium and linear strain distribution across the section lead to

$$
\begin{gathered}
\left(0,85 f_{c}^{\prime}\right) \times\left(\beta_{1} c\right) \times b=A_{s t} f_{y}+A_{f} f_{f}, \\
f_{f}=E_{f} \times \varepsilon_{f}=E_{f} \times\left(\frac{d_{f}-c}{c}\right) \varepsilon_{c u} .
\end{gathered}
$$

Substitute (14) into (13) and then solve a quadratic equation for $c$. The nominal value of the flexural capacity $\left(M_{n}\right)$ can be calculated by

$$
\begin{aligned}
M_{n}= & \left(0,85 f_{c}^{\prime}\right) \times\left(\beta_{1} c\right) \times b \times\left(c-\frac{\beta_{1} c}{2}\right)+ \\
& A_{s t} f_{y} \times\left(d_{s t}-c\right)+A_{f} f_{f} \times\left(d_{f}-c\right) .
\end{aligned}
$$

In contrast when an under-reinforced section is designed, the FRP rods are expected to break and yielding of steel occurs at ultimate state. Internal force equilibrium gives rise to

$$
\left(0,85 f_{c}^{\prime}\right) \times\left(\beta_{2} c\right) \times b=A_{s t} f_{y}+A_{f} f_{f u} .
$$

And thus

$$
c=\frac{A_{s t} f_{y}+A_{f} f_{f u}}{0,85 f_{c}^{\prime} \beta_{2} b}
$$

where $\beta_{2}$ is the ratio of the depth of the equivalent stress block to the neutral axis depth when the maximum concrete strain is less than its ultimate value. When a linear stress profile of concrete is used, $\beta_{2}$ can be calculated by equating the force of concrete stress profile and that of equivalent stress block. Having determined the value for $c, M_{n}$ can be determined by

$$
\begin{aligned}
M_{n}= & \left(0,85 f_{c}^{\prime}\right) \times\left(\beta_{2} c\right) \times b \times\left(c-\frac{\beta_{2} c}{2}\right)+ \\
& A_{s t} f_{y} \times\left(d_{s t}-c\right)+A_{f} f_{f u} \times\left(d_{f}-c\right) .
\end{aligned}
$$

However, when over-reinforced beam section in region 2 is used (ie concrete crushes, steel remains in elastic range at ultimate state), internal force equilibrium results in

$$
\left(0,85 f_{c}^{\prime}\right) \times\left(\beta_{1} c\right) \times b=A_{s t} f_{s t}+A_{f} f_{f}
$$

Linear strain distribution is assumed and thus gives rise to (20) and (21).

$$
f_{s t}=E_{s t} \times \varepsilon_{s t}=E_{s t} \times\left(\frac{d_{s t}-c}{c}\right) \varepsilon_{c u},
$$




$$
f_{f}=E_{f} \times \varepsilon_{f}=E_{f} \times\left(\frac{d_{f}-c}{c}\right) \varepsilon_{c u} .
$$

Substitution of (20) and (21) into (19) leads to a quadratic equation of $c$. By solving the value of $c, M_{n}$ can be calculated by

$$
\begin{aligned}
M_{n}= & \left(0,85 f_{c}^{\prime}\right) \times\left(\beta_{1} c\right) \times b \times\left(c-\frac{\beta_{1} c}{2}\right)+ \\
& A_{s t} f_{s t} \times\left(d_{s t}-c\right)+A_{f} f_{f} \times\left(d_{f}-c\right) .
\end{aligned}
$$

If the beam section is under-reinforced (ie FRP breaks and steel in elastic range), (19) becomes (23):

$$
\left(0,85 f_{c}^{\prime}\right) \times\left(\beta_{2} c\right) \times b=A_{s t} f_{s t}+A_{f} f_{f u} .
$$

The steel stress can be calculated by Eq (24):

$$
f_{s t}=E_{s t} \times \varepsilon_{s t}=E_{s t} \times\left(\frac{d_{s t}-c}{d_{f}-c}\right) \varepsilon_{f u} .
$$

Finally the equation for $M_{n}$ is formed:

$$
\begin{aligned}
M_{n}= & \left(0,85 f_{c}^{\prime}\right) \times\left(\beta_{2} c\right) \times b \times\left(c-\frac{\beta_{2} c}{2}\right)+ \\
& A_{s t} f_{s t} \times\left(d_{s t}-c\right)+A_{f} f_{f u} \times\left(d_{f}-c\right) .
\end{aligned}
$$

Non-dimensional plots of $\left(M_{n} / f_{c}^{\prime} b d_{f}^{2}\right)$ against $\left(A_{f} b d_{f}\right)$ for a beam section in regions 1 and 2 are given in Figs 6 and 7 respectively. To generate these plots, the values used in addition to the previously assumed data are $d_{s t} / d_{f}=0,4$ for Fig 6 and $d_{s t} / d_{f}=0,3$ for Fig 7.

As in the two design charts (Figs 6 and 7), the nondimensional flexural capacity increases with the non-dimensional FRP area for any beam section in region 1 or

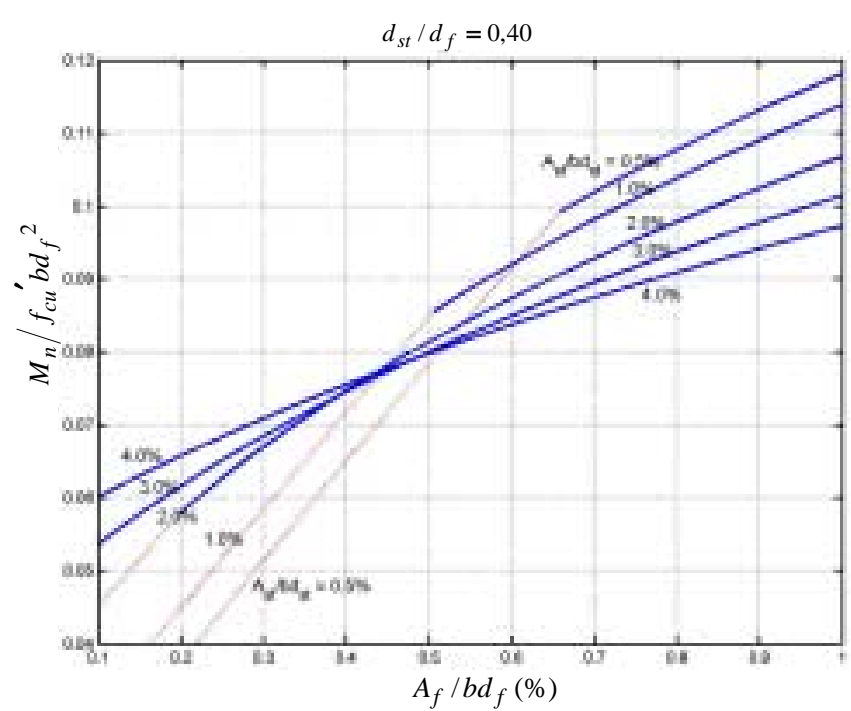

Fig 6. $\left(M_{n} / f_{c}^{\prime} b d_{f}^{2}\right)$ against $\left(A_{f} / b d_{f}\right)$ for a beam section in region 1

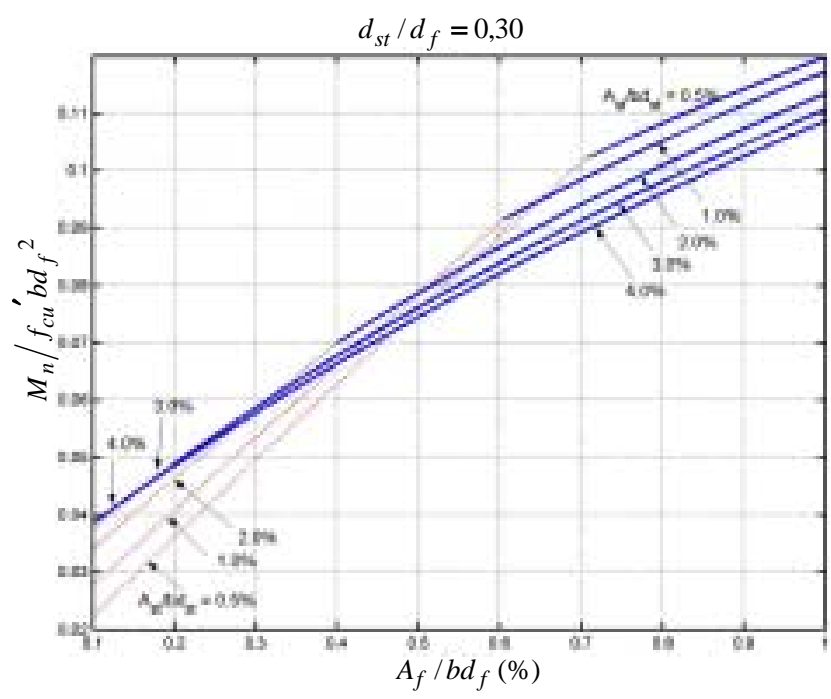

Fig 7. $\left(M_{n} / f_{c}^{\prime} b d_{f}^{2}\right)$ against $\left(A_{f} / b d_{f}\right)$ for a beam section in region 2

2. The dotted lines show under-reinforced beam sections, whereas solid lines indicate over-reinforced sections.

\section{Comparisons with experiments}

The theoretical flexural strengths are compared with the results of an experimental study. A total of eight concrete beams internally reinforced with steel rebars and GFRP rods were tested in which four beams were cast with low-strength concrete $(\sim 35 \mathrm{MPa})$ and the rest were made of medium-strength concrete $(\sim 60 \mathrm{MPa})$. Ordinary Portland cement was used to make the concrete. The detailed mix proportions are given in Table 1. All beams were cast horizontally.

Table 1. Concrete mix proportions

\begin{tabular}{c|c|c}
\hline Materials quantity $\left(\mathrm{kg} / \mathrm{m}^{3}\right)$ & Mix 1 & Mix 2 \\
\hline Ordinary Portland cement & 340 & 530 \\
\hline $20 \mathrm{~mm}$ aggregates & 720 & 850 \\
\hline $10 \mathrm{~mm}$ aggregates & 370 & 365 \\
\hline Sand & 720 & 450 \\
\hline Water & 210 & 185 \\
\hline Sctual concrete cube strength $(\mathrm{MPa})$ & -- & 1.62 \\
\hline
\end{tabular}

Two different kinds of reinforcement were adopted at two different levels in the tension zone of all beam specimens. High-yield steel deformed bars and glass fibre-reinforced polymer (GFRP) composite rods were used. The high-yield steel reinforcing rebars were of diameter $10 \mathrm{~mm}$ and they had a yield strength and elastic modulus of $460 \mathrm{MPa}$ and $200 \mathrm{GPa}$ respectively. The two kinds of GFRP rods adopted were manufactured by 
Hughes Brothers Inc. USA and Pultrall, ADS Composites Group, Canada. These GFRP composite rods were made from high-strength E-glass fibres and a durable resin matrix through a pultrusion process. A wide range of bar diameter is available in the market and a diameter of $3 / 8$ inch was selected because its nominal size $(9,53 \mathrm{~mm})$ was comparable to that of the steel rebar adopted. Tensile tests were performed and results indicated that the tensile strength and elastic modulus of the two GFRP rod types were $760 \mathrm{MPa}$ and 40,8 GPa and $703 \mathrm{MPa}$ and 41,7 GPa respectively.

The total depth of the beam section was $200 \mathrm{~mm}$ and the distances between the bottom surface of the beam and the centreline of the steel rebars and GFRP rods were 70 and $40 \mathrm{~mm}$ respectively. In addition to the hybrid flexural reinforcements, minimum shear reinforcing stirrups was also designed at two shear spans.

Testing of specimens was conducted using a fourpoint bending setup. Each of the 2,5 m long specimens were tested over a total span of 2,2 $\mathrm{m}$ with a shear span of $0,7 \mathrm{~m}$ at both ends, leaving a constant bending region of $0,8 \mathrm{~m}$.

Some input data is listed below and more details can be found in Table 2 .

$$
\begin{array}{ll}
b=150 \mathrm{~mm} & d_{s t}=130 \mathrm{~mm} \\
A_{s t}=157,1 \mathrm{~mm}^{2} & A_{s t} /\left(b d_{s t}\right)=0,81 \% \\
f_{y}=460 \mathrm{Mpa} & E_{s t}=200 \mathrm{GPa} \\
d_{f}=160 \mathrm{~mm} & d_{s t} / d_{f}=0,81
\end{array}
$$

According to the beam details, the theoretical moment capacity for each beam was calculated (Table 2). It is clear that the theoretical ultimate moments match with the experimental ultimate moments with reasonable accuracy. Without taking into account the effects from tension stiffening and compression steel, an underestimated ultimate moment is found.

Additionally, it was observed that the strain of steel for all beams exceeded its yielding value and the beam failure modes were largely governed by crushing of compression concrete except for the last two specimens in which rupture of GFRP rod occurred. This confirms that the all beams are categorised in region 1 and increase in concrete compression capacity in the last two beam-sections lead to brittle GFRP-rupture.

\section{Conclusions}

From the present study, the following conclusions can be drawn.

Since a balanced beam section is governed only by the ultimate strains of compression concrete and outer FRP rods, the depth of the internal steel rebars plays an important role in its ultimate behaviour. Three distinct regions in a $\left(d_{s t} / d_{f}\right)-\varepsilon_{f u}$ plot can be developed and the steel rebars may (1) yield; (2) remain in its elastic state; or (3) be subject to compression at the ultimate stage of the section.

A simple chart which allows a quick check of the reinforcement areas for a balanced beam section has been developed. It is found that when the FRP rods are located closer to the bottom of the beam, the steel ratio $A_{s t}\left(b d_{s t}\right)$ is inversely proportional to the FRP ratio $A_{f}\left(b d_{f}\right)$.

There exists a limiting value of $A_{s t}\left(b d_{s t}\right)$ for a particular ratio of $\left(d_{s t} / d_{f}\right)$. When the designed value of $A_{s t}\left(b d_{s t}\right)$ is greater than this limiting value, the beam section must be over-reinforced irrespective of the $A_{f}\left(b d_{f}\right)$ values.

Design charts of $M_{n}\left(f_{c}^{\prime} b d_{f}^{2}\right)$ for any combinations of $A_{f}\left(b d_{f}\right)$ and $A_{s t}\left(b d_{s t}\right)$ have been developed.

\begin{tabular}{|c|c|c|c|c|c|c|c|c|}
\hline Beam number & $\begin{array}{c}f_{c u} \\
(\mathrm{MPa})\end{array}$ & $\begin{array}{c}A_{f} \\
\left(\mathrm{~mm}^{2}\right)\end{array}$ & $\begin{array}{c}f_{f u} \\
(\mathrm{MPa})\end{array}$ & $\begin{array}{c}E_{f} \\
(\mathrm{GPa})\end{array}$ & $\begin{array}{l}\frac{A_{f}}{b d_{f}} \\
(\%)\end{array}$ & $\begin{array}{c}M_{n(\exp )} \\
(\mathrm{kNm})\end{array}$ & $\begin{array}{c}M_{n(\text { theo })} \\
(\mathrm{kNm})\end{array}$ & $\frac{M_{n(\text { theo })}}{M_{n(\exp )}} \times 100 \%$ \\
\hline L2 & 35,6 & 142,7 & 760 & 40,8 & 0,59 & 22,2 & 17,6 & $79,3 \%$ \\
\hline L4 & 35,6 & 142,7 & 703 & 41,7 & 0,59 & 20,7 & 17,8 & $86,0 \%$ \\
\hline L5 & 35,6 & 214,0 & 760 & 40,8 & 0,89 & 23,1 & 20,0 & $86,6 \%$ \\
\hline L7 & 35,6 & 214,0 & 703 & 41,7 & 0,89 & 23,0 & 20,1 & $87,4 \%$ \\
\hline $\mathrm{H} 2$ & 61,0 & 142,7 & 760 & 40,8 & 0,59 & 21,1 & 20,6 & $97,6 \%$ \\
\hline $\mathrm{H} 4$ & 61,0 & 142,7 & 703 & 41,7 & 0,59 & 21,4 & 20,6 & $96,3 \%$ \\
\hline H5 & 61,0 & 214,0 & 760 & 40,8 & 0,89 & 27,1 & 23,7 & $87,4 \%$ \\
\hline $\mathrm{H} 7$ & 61,0 & 214,0 & 703 & 41,7 & 0,89 & 27,0 & 23,9 & $88,5 \%$ \\
\hline
\end{tabular}
It allows a quick estimate of the flexural capacity of the designed beam section.

\section{References}

1. American Concrete Institute. Building code requirements for reinforced concrete ACI 318-95 and commentary (318R95), Farmington Hills, Michigan, 1995.

Table 2. Comparisons of ultimate moments 
2. British Standards Institution. Structural use of concrete. Part 1. Code of practice for design and construction BS 8110-1. Part 1:1997, BSI, 389 Chiswich High Road, London W4 4AL, 1997.

3. American Concrete Institute. Guide for design and construction of concrete reinforced with FRP bars ACI 440.1R01, Farmington Hills, Michigan, 2001.

4. Granga, Rao H. V. S.; Faza, S. S.; and Anderson, A. Designing concrete beams with FRP rebars. Proceedings of the Concrete 2000 Conference, 1993, p. 1847-1856.

5. Benmokrane, B.; Chaallal, O.; and Masmoudi, R. Glassfibre reinforced plastic (GFRP) rebars for concrete structures. Construction and Building Materials, Vol 9, No 6, 1995, p. 353-364.

6. Theriault, M.; and Benmokrane, B. Effects of FRP reinforcement ratio and concrete strength on flexural behaviour of concrete beams. Journal of Composites for Construction, ASCE, Vol 2, No 1, 1998, p. 7-16.
7. Grace, N. F.; Soliman, A. K.; Abdel-Sayed, G.; and Saleh, K. R. Behavior and ductility of simple and continuous FRP reinforced beams. Journal of Composites for Construction, ASCE, Vol 2, No 4, 1998, p. 186-194.

8. Masmoudi, R.; Theriault, M.; and Benmokrane, B. Flexural behavior of concrete beams reinforced with deformed fiber reinforced plastic reinforcing rods, ACI Structural Journal, Vol 95, No 6, 1998, p. 665-676.

9. Alsayed, S. H.; Al-Salloum, Y. A.; and Almusallam, T. H. Performance of glass-fiber reinforced plastic bars as a reinforcing material for concrete structures. Composites Part B: Engineering, Vol 31, 2000, p. 555-567.

10. Peece, M.; Manfredi, G.; and Cosenza, E. Experimental response and code models of GFRP RC beams in bending. Journal of Composites for Construction, ASCE, Vol 4, No 4, 2000, p. 182-190.

11. Toutanji, H.; and Saafi, M. Flexural behavior of concrete beams reinforced with glass fiber-reinforced polymer (GFRP) bars. ACI Structural Journal, Vol 97, No 5, 2000, p. 712-719. 